Article

\title{
Financial Deepening, Spatial Spillover, and Urban-Rural Income Disparity: Evidence from China
}

\author{
Maosheng Ran, Liang Chen * ${ }^{-1}$ and Wanli Li
}

School of Economics and Business Administration, Chongqing University, Chongqing 400030, China; ranmaosheng@cqu.edu.cn (M.R.); 20160201035@cqu.edu.cn (W.L.)

* Correspondence: 20170201015@cqu.edu.cn; Tel.: +86-182-23090012

Received: 24 December 2019; Accepted: 11 February 2020; Published: 15 February 2020

check for updates

\begin{abstract}
Financial development is one of the main sources of economic growth, whether financial deepening can lower the income inequality between urban and rural areas has been the focus of policy makers and researchers. Using data from 31 provinces in China, from 2002 to 2013, this paper examines the impact of financial deepening on income inequality between urban and rural areas. These empirical results show that financial deepening is significantly negatively associated with urban-rural income disparity, that is, for every $1 \%$ increase in financial deepening urban-rural income disparity can be reduced by about $0.5 \%$. Further research has investigated that the influence of financial deepening on income disparity has a selective effect. From the decomposition effect of financial deepening, we also find that the proximity effect of the Eastern and Central regions is higher than that of the local effect, while the local effect of the Western region is higher than that of the Eastern and Central regions, but the proximity effect is not significant. The conclusion of this paper is of great significance to further deepen financial reform, improve the quality of financial development, and achieve sustainable development of economy.
\end{abstract}

Keywords: urban-rural income disparity; financial deepening; spatial spillover effect; sustainable development

\section{Introduction}

Since the reform and opening-up, China's economy has made remarkable achievements. However, the rapid economic development is accompanied by the widening income disparity between urban and rural areas. The World Income Inequality Database (2018) notes that China's Gini index has remained above 0.43 in recent years, which is not only higher than many developed countries but also most developing countries. Uneven income distribution is the main reason for the widening income disparity among Chinese. According to the data from National Bureau of Statistics (NBS), the per capita disposable income in 2018 was 28,228 yuan. Among them, the per capita disposable income of urban residents was 39,251 yuan; while that of rural residents was 14,617 yuan, with a difference of 2.68 times. The distortion of income structure and the continuous expansion of the income disparity between urban and rural areas not only affect the sustainable development of the economy, but also seriously affect social fairness and stability. Lu and Chen pointed out that ignoring income inequality while pursuing economic growth may lead to social unrest like that in Latin American countries, which in turn will affect long-term economic growth [1]. Wang and Fan also believe that the deterioration of income distribution poses a serious challenge to social justice, leading to increasing social conflicts and may affect economic growth in future [2]. However, Chao and Shen also emphasized that many structural contradictions have accumulated in the process of rapid economic growth in China. With the 
transformation of the economic structure from manufacturing to service, China's economy is gradually entering a new phase of structural deceleration. The downward shift in growth has caused hidden risks in distribution, employment, taxation, and finance contradictions to continue to manifest [3].

However, as the core resource of modern economic development, financial deepening plays a pivotal role in the composition and distribution of residents' income, which has a huge impact on the urban-rural income disparity. On the one hand, as China's financial development is generally underdeveloped, the financial development levels of various regions also show a large disparity, resulting in a serious imbalance in the spatial allocation of financial resources [4]. A few developed regions in the east have huge financial resources, while the central and western regions, especially in rural areas, lack financial resources urgently. On the other hand, with the popularization and improvement of financial infrastructure represented by financial institutions and intermediaries, this facilitates the availability of financial resources and greatly reduces the finance cost of the residential sector, especially providing more convenient financial services to less developed areas and low-income people.

Compared with previous studies, the marginal contribution of this paper is mainly reflected in the following three aspects. First, most existing studies focus on the impact of financial deepening on economic growth $[5,6]$, but few directly discuss the relationship between financial deepening and urban-rural income disparity. This paper analyzes this mechanism by using empirical research methods, providing empirical evidence for how financial deepening affects the income disparity in China, and enriches and expands relevant research literature on financial deepening and income disparity between urban and rural areas. Second, due to the spatial spillover effect between financial deepening and urban-rural income disparity, traditional econometric methods may lead to biased estimates [7]. Therefore, based on the spatial lag model (SLM), this paper presents a quantitative analysis of spatial spillover effects in China. Third, previous literature seldom considers the regional selection effect of financial deepening on the income disparity between urban and rural areas. However, this paper found that financial deepening has a significant selection effect on reducing income disparity through the study of subregions in China.

The rest of the study is as follows: part two is a literature review. The third part presents research and design. The fourth part is an empirical analysis. The fifth part is the research conclusion and the final presents limitations and future research.

\section{Literature Review}

Presently, there are few direct studies on financial deepening and income disparity, but more on the topic from the perspective of economic growth [8-10]. Since Goldsmith's groundbreaking discovery in 1969, a large number of studies on the relationship between financial deepening and economic growth have been undertaken [11]. Greenwood and Jovanovic use endogenous growth models to illustrate how financial development promotes economic growth [12]. Since then, these theoretical contributions have been supplemented by empirical research, providing theoretical and empirical support for assumption that financial development promotes economic growth. By distinguishing the long-term and short-term effects of financial deepening on economic growth, Levine et al. found that financial deepening has a significant effect on long-term economic growth in developed regions, while the short-term effects on developing regions are more significant [12]. Research by King and Levine also shows that financial development has a positive impact on economic growth and capital accumulation in most countries [13]. Borlea et al. (2016) empirically studied the causal relationship between financial development and economic growth by using the World Bank Development Database and found that there is a close relationship between financial development and economic growth. Based on different regional samples and different financial development indicators, there are also some differences in the causal relationship between financial and economic growth. For some regions, financial development promotes economic growth and is a one-way relationship. However, there is a two-way causal relationship between financial development and economic growth in some regions. 
Although these empirical studies show that financial deepening has enhanced economic growth potential, the underlying mechanism still needs more detailed analysis [14]. Therefore, this paper puts forward the following research assumptions:

Assumption 1: Financial deepening significantly promotes regional economic growth.

Although the relationship between financial deepening and economic growth has been extensively studied, there is little research on income inequality. Moreover, the theoretical research on this issue has produced controversial results, and a consensus has not yet been reached in the literature. The first type of research found that unequal access to finance is the key mechanism that causes persistent income inequality and slowing of economic growth. Relevant literature emphasizes that imperfect capital markets and loan restrictions that restrict access to finance may affect inequality and poverty in the process of economic development. Persistent financial market imperfections are the key determinants of poverty in many patterns of inequality and poverty (Baiardi and Morana, 2016; Jauch and Watzka, 2016; Bittencourt et al. 2019) [15-17]. These deficiencies prevent low-income people from investing in human capital, health, and entrepreneurial activities. However, in the past quarter-century, income inequality has increased in many countries and the number of people living in absolute poverty has decreased. However, in empirical or theoretical studies, the exact impact of financial development on income inequality and poverty reduction has not been clearly defined. The second type of research found that financial deepening will help reduce income inequality (Banerjee and Newman, 1993; Altunbaş et al. 2019; Thornton and Tommaso, 2019) [18-20]. Mookherjee and Ray (2003) pointed out that as the development of financial markets will provide wider and easier access to credit for poor families, credit restrictions faced by low-income people will be eased, which in turn will help reduce poverty [21]. Thornton and Tommaso (2019) stressed that in the long run, financial development will reduce income inequality and will have a strong impact on the results of different financial deepening measures and income groups in different countries. Hamori and Hashiguchi (2012) used panel data from 126 countries to analyze the impact of financial deepening on inequality. They found that financial deepening reduced inequality, but economic growth reduced the equalization effect of financial deepening [22]. Clarke et al. (2006) used data from 83 developed and developing countries from 1980 to 1995 to study the impact of financial deepening on income inequality measured by the Gini coefficient. As representatives of financial deepening, they use two indicators: credit from the private sector divided by Gross Domestic Product (GDP), and bank deposits' claims on domestic non-financial sectors divided by GDP. Empirical results show that financial deepening reduces income inequality [23]. Beck et al. (2007) used data from 52 developing and developed countries from 1960 to 2005 to investigate the relationship between the development of financial intermediation and changes in income distribution. This study found that financial deepening reduced the growth rate of the Gini coefficient and increased the income growth rate of the poor [24]. However, Bittencourt et al. (2019) used a fixed-effect estimation method to examine the effect of financial development on state-level income inequality in 50 US states from 1976 to 2011. They have found that financial development has linearly increased income inequality in 50 states. When they divide 50 states into two different inequality states above and below average, the impact of financial development on income inequality appears to be non-linear. When financial development improves, for higher-than-average income inequality, this effect increases at an increasing rate, and for lower-than-average income inequality, there is an inverted U-shaped relationship. The third category is mainly domestic scholars studying the impact of financial development and financial deepening on urban-rural income inequality. Dong and Zhang (2013) believe that the improvement of financial deepening has widened the income gap between urban and rural residents, and there is an inverted " $U$ " relationship between financial deepening and the income gap between urban and rural residents, that is, the income gap between urban and rural residents can be narrowed only after financial deepening reaches a certain level [25]. Yang et al. (2006) used time series data to analyze the impact of finance on the income gap between urban and rural areas. The research found that due to the lag of financial intermediary and other fields, financial development 
has significantly widened the income gap between urban and rural areas in China and exacerbated income inequality [26]. However, Zhang et al. (2010) obtained the opposite result by using macro data. This study found that in the long run, with the deepening of China's finance, it will help reduce income inequality between urban and rural areas. Although contrary to most domestic research conclusions, it confirms the linear negative correlation hypothesis proposed by Galor and Zeira between financial development level and income distribution inequality. The results of this study show that financial development is not the cause of the widening income disparity in China, but the real reason may lie in the income distribution mode [27]. Therefore, this paper puts forward the second research hypothesis:

Hypothesis 2: Financial deepening can reduce income disparity between urban and rural areas.

In a word, financial deepening will definitely affect the income disparity between urban and rural areas, but the quantitative relationship is relatively uncertain. Currently, the focus of academic research is the impact of financial deepening on economic growth. Few studies discuss the relationship between financial deepening and income disparity between urban and rural areas. In addition, more attention is paid to the income inequality of residents in the study, and less is given to the income disparity between them within the region and the role of geographical factors. However, compared with economic growth, the urban-rural income disparity not only focuses on the growth of per capita output, but also on the fair distribution of wealth [28]. Therefore, in the context of achieving targeted poverty alleviation and building a well-off society in an all-round way, it is of theoretical value and practical significance to study the impact of financial deepening on the urban-rural income disparity.

\section{Research Methodology}

\subsection{Spatial Econometric Model Selection}

As financial deepening has spatial spillover effects on the urban-rural income disparity, traditional econometric methods may lead to biased estimates [29]. Therefore, the adoption of a spatial econometric model can effectively overcome this defect. The criteria for selecting the spatial lag model (SLM) or spatial error model (SEM) are mainly based on the significance of Lagrange Multiplier (LM) and its Robustness LM, and the model with better fitting effect is further selected by comparing goodness of fit $R^{2}$. In this study, Stata 15 was used for maximum likelihood estimation. Wald test and LR test were used to test whether the spatial Dubin model (SDM) model can be simplified to the SLM model or SEM model. The test results show that all models reject the SDM model and select the SLM model. In addition, we used the Hausman test to decide whether to use a random effect model or fixed effect model.

This paper comprehensively analyzes the impact mechanism of urban-rural income disparity from the perspective of financial deepening. Due to the significant correlation between financial deepening and income disparity in geographical space, if this spatial correlation is not taken into account in the construction of the model, certain errors will occur in the measurement results. Therefore, according to the above research method, we set the SLM as follows:

$$
\text { Disparity }_{i t}=\beta_{0}+\beta_{1} \text { Findep }_{i t}+\rho \sum W_{i j} \text { Disparity }_{i t}+\beta_{k} D_{i t}+\mu_{i}+\varepsilon_{i t}
$$

In Equation (1), Disparity represents the income disparity between urban and rural areas; Findep stands for financial deepening; $\sum w_{i j}$ Disparity $_{j t}$ is the spatial lag dependent variable; $D_{\mathrm{it}}$ is a series of control variables; $\varepsilon_{\mathrm{it}}$ is a random error term; $\mu_{\mathrm{i}}$ indicates the individual effect, and intrinsic geographical and cultural factors in the region that do not change with time; $\rho$ is a spatial autoregressive coefficient, and its estimated value reflects the direction and magnitude of spatial correlation. 


\subsection{Selection of Spatial Weight Matrix}

The traditional distance space weight only considers distance and ignores the influence of the economic scale of neighboring provinces. It is generally believed that the more developed the economy, the greater the influence on backward areas. Therefore, it is necessary to adjust the single distance with the economic scale of neighboring provinces as the weight. The formula is as follows:

$$
\mathrm{W}_{\mathrm{il}}=\left[1 / \mid \text { econvar }_{-\mathrm{i}}-\text { econvar }_{-\mathrm{j}}+1 \mid\right] * \exp \left(-\mathrm{b} * \mathrm{D}_{\mathrm{dij}}\right)
$$

where $D_{-i j}$ is the distance between I and $j$, econvar_i refers to the economic scale index of $i$ region, such as the proportion of GDP in the GDP of all regions, where the molecule takes the form of absolute value, and $\mathrm{D}_{\mathrm{ij}}$ represents the distance between the two regions, which is generally calculated according to the latitude and longitude distance. Relevant scholars [30,31] use economic or social networks as the spatial weight matrix, mainly including GDP, industrial added value, operating income, total labor remuneration, etc. This paper used the GDP-based row random space weight matrix and the 0-1 matrix as the regression weight matrix for the comparative test.

\subsection{Descriptive Statistics of Data}

The data include 31 provinces in mainland China from 2002 to 2013. The data mainly come from the statistical yearbooks of China's provinces, and the financial deepening data mainly come from China's financial statistical yearbooks, and GDP and related control variables are all from China Statistical Yearbook.

The descriptive statistics of related variables in Table 1 show that the maximum and minimum values of urban-rural income disparity are 1.75 and 5.1, respectively, with a difference of about three times. This shows that the income disparity between urban and rural areas in China is relatively large, and from a dynamic perspective, the income disparity between urban and rural areas in China has been widening year by year since the reform and opening-up. The maximum value and minimum value of financial deepening are 0.5 and 2.98, respectively, which shows that there is a big disparity in the level of financial deepening between different provinces. From the per capita GDP, the highest per capita income is 99,607, while the lowest province's per capita income is 3257 , a difference of more than 30 times. The regional distribution of per capita income varies greatly, which is also an important reason for the per capita income disparity between urban and rural areas.

Table 1. Description of variables.

\begin{tabular}{cccc}
\hline Variable & Definition & Mean & Standard Deviation \\
\hline Disparity & $\begin{array}{c}\text { Urban-rural income disparity = per capita disposable income of } \\
\text { urban residents/per capita disposable income of rural residents }\end{array}$ & 3.038 & 0.6333 \\
Findep & $\begin{array}{c}\text { Financial deepening = balance of loans from banks and financial } \\
\text { institutions/GDP }\end{array}$ & 1.036 & 0.369 \\
& $\begin{array}{c}\text { Capital stock refers to all the existing capital resources of an } \\
\text { enterprise, which can usually reflect the existing production and } \\
\text { operation scale and technical level of the enterprise }\end{array}$ & 0.557 & 0.142 \\
PGDP & PGDP = GDP/total population, 1978 = 100 & 25861 & 18928 \\
Urb & Urbanization = urban population/total population & 0.475 & 0.151 \\
Fiscal & Fiscal expenditure = governments expenditure/GDP & 0.462 & 0.08 \\
Openness & Openness = total value of imports and exports/GDP & 0.334 & 0.417 \\
Consume & Consumption Rate = total consumption/GDP & 0.520 & 0.0915 \\
Pop & $\begin{array}{c}\text { Dependency ratio of population = the ratio of non-working age } \\
\text { population to working-age population in the total population }\end{array}$ & 0.372 & 0.070 \\
Stru & $\begin{array}{c}\text { Industrial structure = added value of second industry/added value of } \\
\text { tertiary industry }\end{array}$ & 0.873 & 0.064 \\
Hum & Human capital = the proportion of undergraduate and specialized \\
students/total population & 0.226 & 0.095 \\
\hline
\end{tabular}




\section{Empirical Results}

Due to the obvious spatial correlation and spatial spillover effect between financial deepening and urban-rural income disparity, traditional econometric methods may produce estimation bias. Therefore, using a spatial econometric model can effectively overcome the original research defects. Conventional spatial econometric models include the spatial lag model (SLM), spatial error model (SEM), and spatial Dubin model (SDM). Before using the spatial econometric model, this paper needs to carry out a spatial autocorrelation test.

\subsection{Spatial Autocorrelation Analysis}

The Moran index is distributed in $[-1,1]$, which is used to judge whether there is autocorrelation in space. It is used to determine whether there is a correlation between spatial entities within a certain range. Moran index values are distributed in $[-1,1],[0,1]$ indicating that there is a positive correlation between geographical entities, and $[-1,0]$ indicating that there is a negative correlation, while 0 values have no correlation.

Table 2 lists Global Moran index and Geary values of 31 provincial urban-rural income disparity in 2002 and 2013 under two weights. It can be seen that the Moran index of 0-1 weight matrix is about 0.6 , Moran index of economic weight matrix is 0.3 , and Geary value of economic weight matrix is about 0.45 . From 2002 to 2013, the Moran and Geary value of urban-rural income disparity exceeded 0.5 and 1, respectively, and both passed the significance level test of $1 \%$, which indicates that there is a significant positive spatial correlation between urban-rural income disparity in China. The research shows that geographical factors and spatial effects play a pivotal role in the study of China's urban-rural income disparity, and the spatial influence factors of the explained variables should be included in the econometric model.

Table 2. Global Moran index of income disparity between urban and rural areas in China.

\begin{tabular}{|c|c|c|c|c|c|c|}
\hline \multirow{2}{*}{ Year } & Global Moran's I & \multirow{2}{*}{$p$-Value } & Global Moran's I & \multirow{2}{*}{$p$-Value } & Geary & \multirow{2}{*}{$p$-Value } \\
\hline & 0-1 Matrix & & Economic Matrix & & Economic Matrix & \\
\hline 2002 & 0.611 & 0.000 & 0.395 & 0.001 & 0.376 & 0.005 \\
\hline 2003 & 0.626 & 0.000 & 0.392 & 0.002 & 0.388 & 0.002 \\
\hline 2004 & 0.597 & 0.000 & 0.330 & 0.006 & 0.444 & 0.004 \\
\hline 2005 & 0.576 & 0.000 & 0.316 & 0.008 & 0.453 & 0.003 \\
\hline 2006 & 0.558 & 0.000 & 0.332 & 0.006 & 0.432 & 0.003 \\
\hline 2007 & 0.599 & 0.000 & 0.343 & 0.005 & 0.417 & 0.001 \\
\hline 2008 & 0.605 & 0.000 & 0.319 & 0.008 & 0.429 & 0.001 \\
\hline 2009 & 0.541 & 0.000 & 0.268 & 0.019 & 0.497 & 0.005 \\
\hline 2010 & 0.529 & 0.000 & 0.275 & 0.018 & 0.486 & 0.004 \\
\hline 2011 & 0.517 & 0.000 & 0.274 & 0.017 & 0.493 & 0.006 \\
\hline 2012 & 0.513 & 0.000 & 0.274 & 0.017 & 0.494 & 0.007 \\
\hline 2013 & 0.508 & 0.000 & 0.272 & 0.018 & 0.498 & 0.007 \\
\hline
\end{tabular}

Notes: Authors' own calculation.

A Moran scatterplot can divide the urban-rural income disparity of each province into four quadrants: the first quadrant $(\mathrm{HH})$ indicates that time-series; the second quadrant $(\mathrm{LH})$ indicates that the low-income disparity is surrounded by other provinces with high-income disparity; the third quadrant (LL) indicates that the low-income disparity is surrounded by other provinces that are also low-income disparity; the fourth quadrant (HL) indicates that the high-income disparity is surrounded by other provinces with low-income disparity. The first and third quadrants show positive spatial autocorrelation, while the second and fourth quadrants show negative spatial autocorrelation. The spatial correlation model of financial deepening is the same as above.

A Moran scatterplot between income disparity and financial deepening (see Figures 1 and 2) shows that most provinces are located in the first quadrant $(\mathrm{HH})$ and the third quadrant (LL). In the 
distribution of urban-rural income disparity, 12 provinces were located in the first quadrant in 2013, three more than in 2002. In 2013, nine provinces were located in the third quadrant, consistent with 2002. On the whole, the Moran index of urban-rural income disparity in 2002 and 2013 accounted for $73.33 \%$ and $76.67 \%$ of the total sample, respectively. A Moran scatterplot of financial deepening shows that four and seven provinces were located in the first quadrant in 2002 and 2013, respectively, and 11 provinces were located in the third quadrant in 2013, two more than in 2000. Therefore, in 2002 and 2013, the Moran index of financial deepening in the first and third quadrants accounted for $63.33 \%$ and $66.67 \%$ of the total sample, respectively. This result further confirms that there is a significant spatial positive correlation between the financial deepening in China's provinces and the income disparity between urban and rural areas. Most provinces have similar characteristics with their neighboring provinces. Provinces with higher financial deepening are spatially adjacent to each other, while provinces with lower financial deepening tend to be concentrated. Similarly, provinces with high urban-rural income disparity are surrounded by neighboring provinces with large urban-rural income disparity, while provinces with low urban-rural income disparity are surrounded by neighboring provinces with low urban-rural income disparity.
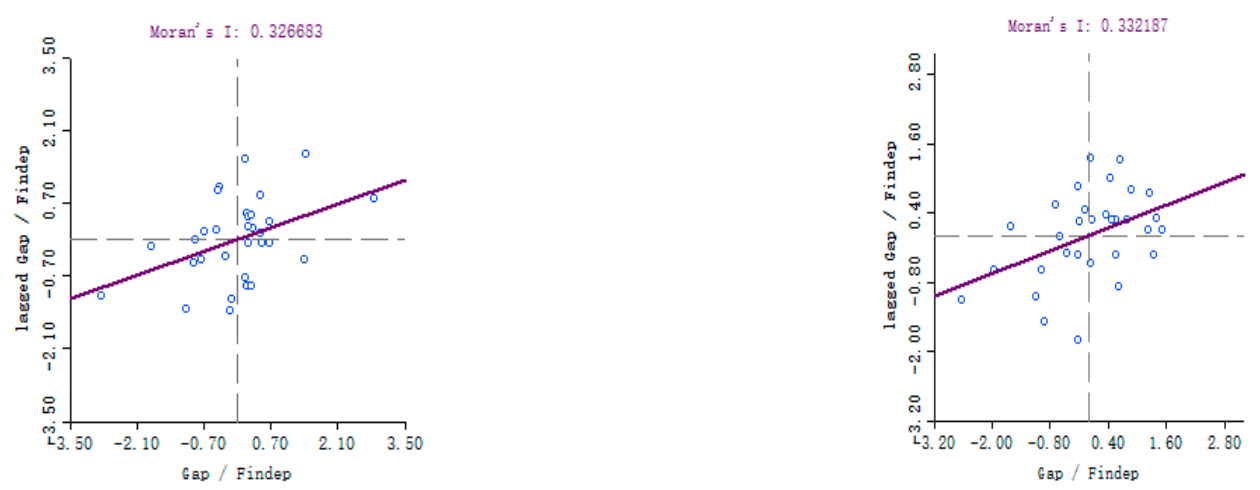

Figure 1. Moran scatterplot of income disparity between urban and rural areas in 2002 and 2013.
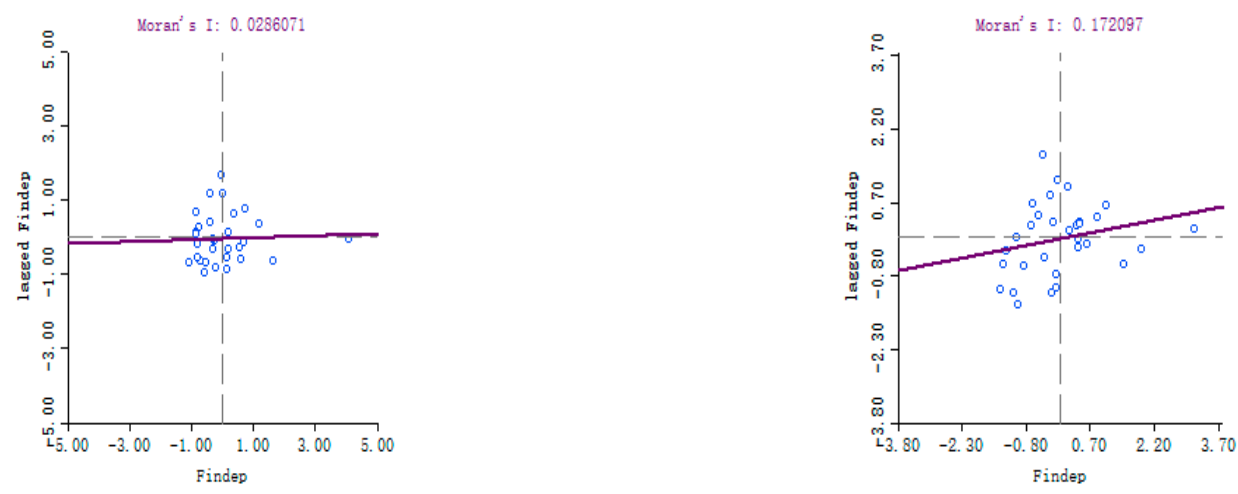

Figure 2. Moran scatterplot of financial deepening between urban and rural areas in 2002 and 2013.

\subsection{Spatial Distribution Characteristics of Income Disparity in China}

In order to more intuitively understand the spatial distribution of China's urban-rural income disparity, the local indicators of spatial association(LISA) map in Figure 3 shows the spatial distribution of China's urban-rural income disparity in 2000 and 2013. In 2002, the overall income disparity between urban and rural areas was 3.11. Most areas were darker and had higher values. The income disparity between urban and rural areas was relatively large. Among them, the income disparity between urban and rural areas in Tibet Autonomous Region is more than 5.1, which is about three times that of the eastern region. Generally speaking, the income disparity in the developed areas is relatively small, with Jiangsu, Liaoning, and Zhejiang having the smallest disparity. The central region takes second place, but the income disparity between urban and rural areas in Shaanxi Province is 3.9, 
which is far higher than the national level and the eastern region. The western region is the hardest hit by the income disparity between urban and rural areas in China. The lowest province is Ningxia, but it also exceeds the national level. By 2013, the income disparity between urban and rural areas in China was still widening, from 2366 yuan in 2001 to 24,634 yuan in 2018, with the disparity widening 10 times. The western region is still the region with the largest income disparity, but the proportion of income disparity between urban and rural areas in Xinjiang and Tibet has obviously narrowed. In the eastern region, the income disparity between Guangdong, Jiangsu, Fujian, and Shanghai has widened compared with 2002, while the income disparity between urban and rural areas in other regions is declining. In the central region, the income disparity in Shanxi is widening, and the other provinces are also showing an obvious downward trend.
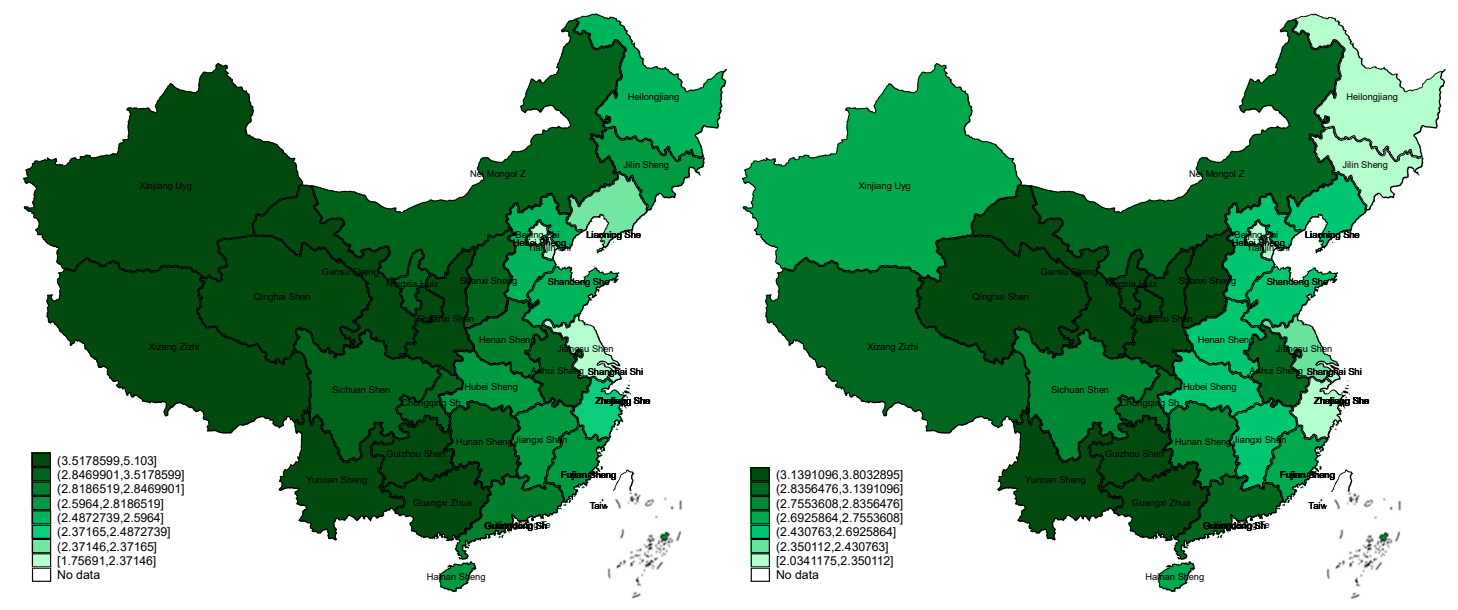

Figure 3. Spatial distribution of income disparity between urban and rural areas in 2002 (left) and 2013 (right).

Overall, from 2002 to 2013, the regional distribution of urban-rural income disparity did not change significantly. Although the proportion has declined, the pattern is relatively stable. There is a ladder distribution from east to west, indicating that the income disparity is the smallest in the east and the highest in the west.

\subsection{Analysis of Regression Results of Total Samples}

From the regression analysis of the total sample in Table 3, models 1-4 are panel fixed effect regression, maximum likelihood regression, and spatial lag regression, respectively. The results show that there is a negative relationship between financial deepening and urban-rural income disparity, indicating that financial deepening helps to reduce the urban-rural income disparity. In models 3 and 4 , the spatial autoregressive coefficient is significantly positive at the level of $1 \%$, which indicates that there is a strong spatial spillover effect between financial deepening and the income disparity between urban and rural areas. However, in contrast to Kuznets' phenomenon that there is an "inverted U" relationship between financial deepening and urban-rural income disparity proposed by Greenwood and Jovanovic, this study finds that there is a significant " $U$ " curve relationship between urban-rural income disparity and GDP per capita in China, that is, with the increase of GDP per capita, the urban-rural income disparity between regions will be significantly reduced in the short term. However, in the long run, economic growth has increased the income disparity of residents, which indicates that urban-rural income distribution mode is no longer suitable for the current economic development situation and needs further reform and adjustment. The improvement of financial deepening level is helpful to narrow the income disparity between urban and rural areas. These results support the theories of Galor and Zeira [5] which are consistent with previous empirical results. At the same time, capital deepening, human capital, and industrial structure all have a restraining effect on the income disparity between urban and rural areas. 
Table 3. Analysis of regression results of total samples.

\begin{tabular}{|c|c|c|c|c|}
\hline \multirow{2}{*}{ Variable } & (1) & (2) & (3) & (4) \\
\hline & FE & MLE & SLM (0-1 Matrix) & SLM (Economic Matrix) \\
\hline \multirow{2}{*}{ Findep } & $-0.356^{* * *}$ & $-0.349^{* * *}$ & $-0.197^{* *}$ & $-0.153^{* *}$ \\
\hline & 0.000 & 0.000 & 0.001 & 0.044 \\
\hline \multirow{2}{*}{ Captial } & $-0.261 * *$ & $-0.233^{* *}$ & -0.138 & -0.08 \\
\hline & 0.023 & 0.038 & 0.155 & 0.453 \\
\hline \multirow{2}{*}{$\operatorname{lnPGDP}$} & $-1.555^{* *}$ & $-1.476^{* *}$ & $-1.051^{* *}$ & $-1.112 * *$ \\
\hline & 0.002 & 0.002 & 0.012 & 0.028 \\
\hline \multirow{2}{*}{$\ln P G D P 2$} & $0.068^{* *}$ & $0.068 * *$ & $0.049 * *$ & $0.055^{* *}$ \\
\hline & 0.006 & 0.005 & 0.02 & 0.032 \\
\hline \multirow{2}{*}{ Openess } & $-0.303^{* *}$ & $-0.336^{* *}$ & $-0.293^{* *}$ & $-0.207^{* *}$ \\
\hline & 0.007 & 0.001 & 0.002 & 0.047 \\
\hline \multirow{2}{*}{ Pop } & -0.025 & 0.168 & 0.154 & 0.466 \\
\hline & 0.953 & 0.68 & 0.66 & 0.238 \\
\hline \multirow{2}{*}{ Ubr } & $1.830^{* * *}$ & $1.167^{* *}$ & $1.192 * *$ & 0.668 \\
\hline & 0.001 & 0.022 & 0.011 & 0.173 \\
\hline \multirow{2}{*}{ Hum } & $-1.511 * *$ & $-1.685^{* * *}$ & $-0.802 *$ & -0.436 \\
\hline & 0.004 & 0.001 & 0.075 & 0.358 \\
\hline \multirow{2}{*}{ Stru } & -0.226 & -0.173 & -0.333 & -0.368 \\
\hline & 0.760 & 0.804 & 0.594 & 0.536 \\
\hline \multirow{2}{*}{ Fiscal } & 0.329 & 0.362 & -0.094 & $-0.533 * *$ \\
\hline & 0.148 & 0.103 & 0.631 & 0.022 \\
\hline \multirow{2}{*}{ Consume } & -0.452 & -0.267 & -0.361 & -0.274 \\
\hline & 0.127 & 0.362 & 0.149 & 0.268 \\
\hline \multirow{3}{*}{$\begin{array}{l}\text { Constant } \\
\text { adj.R-sq }\end{array}$} & $12.12^{* * *}$ & $11.473^{* * *}$ & & \\
\hline & 0.000 & 0.000 & & \\
\hline & 0.195 & & & \\
\hline \multirow{2}{*}{ Spatial rho } & & & $0.554^{* * *}$ & $0.614^{* * *}$ \\
\hline & & & 0.000 & 0.000 \\
\hline \multirow{2}{*}{ Lratio test } & & & $94.14^{* * *}$ & $107.4^{* * *}$ \\
\hline & & & 0.000 & 0.000 \\
\hline \multirow{2}{*}{ Wald test } & & & 6.69 & 5.72 \\
\hline & & & 0.251 & 0.221 \\
\hline $\mathrm{N}$ & 372 & 372 & 341 & 341 \\
\hline
\end{tabular}

Note: ${ }^{* * *}, * *$, and ${ }^{*}$ mean significant at $1 \%, 5 \%$, and $10 \%$ levels, respectively.

As the imbalanced characteristics of China's economic development, namely the unbalanced development between the eastern and inland regions and the uneven development between urban and rural areas, financial deepening will form a regional selection effect [32].

According to the analysis of the regression results of subregions in Table 3, under the condition of financial repression, the artificial financial threshold results in unequal income distribution. Low-income groups in rural areas cannot get high returns due to their capital accumulation restrictions not reaching the wealth threshold level, while high-income groups in urban areas can enjoy high returns due to their advantages in capital accumulation, while financial deepening can break the original financial threshold restrictions. Therefore, financial deepening affects the income disparity between urban and rural areas by the threshold effect mechanism [33]. Regionally, the financial deepening in the western region has a significantly greater effect on reducing the income disparity between urban and rural areas than in the central and eastern regions, and the central region is also greater than the eastern region. In other words, financial deepening has heterogeneity on income inequality between urban and rural areas, while the marginal effect of low-income groups is greater than that of high-income groups. Therefore, with the development of financial deepening, less developed regions can have wider and easier access to credit, and the credit restrictions faced by low-income people will be eased, which in turn will help reduce poverty. At the same time, due to the widespread existence of low-income groups, the income disparity reduction brought about by financial deepening has a significant poverty 
reduction effect and has important reference significance for China's precision poverty alleviation in the new era. In stages, with the increase of per capita output in the eastern region, the income disparity between urban and rural areas began to widen, showing a " $\mathrm{U}$ " structure. With the increase of GDP per capita in the central region, the income disparity between urban and rural areas began to decrease, showing an inverted " $U$ " structure. However, the income disparity between urban and rural areas in the western region has a negative correlation with per capita output.

\subsection{The Decomposition of Spatial Lag Model Effect}

\subsubsection{Total Sample Decomposition Test}

As the spatial regression model studies the complex spatial dependence among spatial individuals, the parameters of the model contain a large amount of information about the relationships among spatial individuals. Changes in the explanatory variables associated with a spatial individual will affect the spatial individual itself, which is the direct effect described by the traditional regression model. At the same time, it will also indirectly affect other spatial individuals and produce an indirect effect. As Behrens and Thisse said, the ability to analyze this indirect effect is an important manifestation of the role of spatial regression models [34]. However, the information contained in the parameters of the spatial regression model also increases the difficulty in interpreting the estimation results.

Therefore, in the spatial econometric model, the regression coefficient of explanatory variables cannot directly reflect its influence on explanatory variables, because the parametric effect of spatial lag model may involve direct effect, indirect effect, and total effect. Therefore, it is necessary to further decompose the total effect into direct effect and indirect effect. Lesage and Pace also pointed out that the $x$ and Wx coefficients in the regression results do not reflect the real spatial effect, and there are certain errors. Therefore, the partial differential method was developed to decompose the effect, and partial derivatives were used to explain the effects brought by the changes of explanatory variables from different models. Tables 4 and 5 decompose the direct effect, indirect effect, and total effect of 31 provinces in China and the eastern, central, and western regions, respectively.

Table 4 describes the total effect decomposition based on 31 provinces in China. The results show that the direct and indirect effects of financial deepening are significantly negative. This shows that financial deepening plays an important role in reducing the income disparity between urban and rural areas in China. In addition, the indirect effect (spillover effect) of financial deepening is close to the direct effect, showing that financial deepening in neighboring regions has a positive impact on the reduction of local income disparity. The possible explanations are as follows: on the one hand, due to the large differences in economic development levels between different regions in China, especially in the financial and capital markets, the developed regions have strong experience in management services and risk control due to the early development of financial markets and high degree of financial deepening. Under the dual effects of market mechanism and spatial spillover effect [35], underdeveloped regions improve their income level through financial services to developed regions, strengthen the financial deepening effect, and reduce the income disparity between urban and rural areas. On the other hand, according to Ndalu, the result of financial deepening will promote limited financial resources to sectors with higher economic benefits, thus promoting the improvement of the productivity level of the whole society and increasing more employment opportunities for the society [35]. Finally, due to credit discrimination in the state-owned banking system, the state-owned banking system is more inclined to lend to state-owned enterprises. Private enterprises and small rural enterprises can hardly get loans from state-owned banks (SOBs). However, most of the state-owned enterprises (SOEs) are located in the middle of cities. China's financial system shows an obvious tendency of urbanization in the allocation of financial resources, which leads to differences in economic development and income growth between urban and rural areas. The unbalanced effect of financial development between urban and rural areas widens the income disparity between urban and rural 
areas [36]. Therefore, once financial deepening starts, its spillover effect will accelerate the local financial deepening effect.

Table 4. Analysis of regression results of subsamples.

\begin{tabular}{|c|c|c|c|c|c|c|}
\hline \multirow{2}{*}{ Variable } & (1) & (2) & (3) & (4) & (5) & (6) \\
\hline & Eastern (FE) & Central (FE) & Western (FE) & Eastern (SLM) & Central (SLM) & Western (SLM) \\
\hline \multirow{2}{*}{ Findep } & $-0.199 * *$ & -0.206 ** & $-0.587^{* * *}$ & -0.135 ** & $-0.197^{* *}$ & $-0.581 * * *$ \\
\hline & 0.002 & 0.014 & 0.000 & 0.011 & 0.007 & 0.000 \\
\hline \multirow{2}{*}{ Captial } & 0.155 & 0.125 & -0.164 & $0.260 * *$ & 0.115 & -0.164 \\
\hline & 0.302 & 0.391 & 0.393 & 0.031 & 0.373 & 0.373 \\
\hline \multirow{2}{*}{$\operatorname{lnPGDP}$} & -0.934 & $5.32 * * *$ & 0.011 & $-1.265 *$ & $3.807^{* * *}$ & -0.017 \\
\hline & 0.318 & 0.000 & 0.990 & 0.088 & 0.000 & 0.984 \\
\hline \multirow{2}{*}{$\operatorname{lnPGDP2}$} & 0.059 & $-0.287^{* * *}$ & -0.0340 & $0.073 * *$ & $-0.207^{* * *}$ & -0.0330 \\
\hline & 0.178 & 0.000 & 0.471 & 0.037 & 0.000 & 0.479 \\
\hline \multirow{2}{*}{ Openess } & -0.011 & $-1.517^{* *}$ & $-1.239 * *$ & -0.074 & $-1.414^{* *}$ & $-1.242 * *$ \\
\hline & 0.889 & 0.004 & 0.014 & 0.246 & 0.002 & 0.009 \\
\hline \multirow{2}{*}{ Pop } & -0.047 & -0.818 & $1.697^{*}$ & 0.220 & $-0.853 *$ & $1.703 *$ \\
\hline & 0.901 & 0.114 & 0.080 & 0.463 & 0.063 & 0.065 \\
\hline \multirow{2}{*}{ Ubr } & $-0.917^{* *}$ & -0.121 & $5.195^{* *}$ & $-0.998 * *$ & -0.018 & $5.245^{* *}$ \\
\hline & 0.042 & 0.871 & 0.007 & 0.005 & 0.979 & 0.004 \\
\hline \multirow{2}{*}{ Hum } & $-1.78^{* * *}$ & $1.607^{* *}$ & -1.483 & $-1.163 * *$ & $1.296^{* *}$ & -1.442 \\
\hline & 0.000 & 0.014 & 0.199 & 0.003 & 0.028 & 0.201 \\
\hline \multirow{2}{*}{ Stru } & 0.74 & 1.038 & 1.575 & $1.733^{* *}$ & $1.077 *$ & 1.535 \\
\hline & 0.474 & 0.137 & 0.316 & 0.037 & 0.082 & 0.311 \\
\hline \multirow{2}{*}{ Fiscal } & -0.221 & -0.033 & 0.562 & $-0.584^{* *}$ & -0.0850 & 0.556 \\
\hline & 0.386 & 0.862 & 0.224 & 0.005 & 0.621 & 0.209 \\
\hline \multirow{2}{*}{ Consume } & $-0.749 *$ & 0.248 & -0.630 & -0.165 & 0.298 & -0.633 \\
\hline & 0.098 & 0.566 & 0.164 & 0.654 & 0.439 & 0.142 \\
\hline \multirow{2}{*}{ Constant } & 6.829 & $-22.375^{* * *}$ & 3.895 & & & \\
\hline & 0.139 & 0.000 & 0.384 & & & \\
\hline $\mathrm{R}^{2}$ & 0.231 & 0.625 & 0.434 & & & \\
\hline \multirow{2}{*}{ Spatial rho } & & & & $0.609 * * *$ & $0.249^{* *}$ & 0.025 \\
\hline & & & & 0.000 & 0.016 & 0.870 \\
\hline $\mathrm{N}$ & 132 & 96 & 144 & 121 & 88 & 132 \\
\hline
\end{tabular}

Note: ${ }^{* * *}, * *$, and $*$ mean significant at $1 \%, 5 \%$, and $10 \%$ levels, respectively.

Table 5. Decomposition of spillover effects for 31 provinces in China.

\begin{tabular}{ccccccc}
\hline \multirow{2}{*}{ Variable } & \multicolumn{2}{c}{ Total Effect } & \multicolumn{2}{c}{ Direct Effect } & \multicolumn{2}{c}{ Indirect Effect } \\
\cline { 2 - 6 } & Coefficient & $p$-Value & Coefficient & $p$-Value & Coefficient & $p$-Value \\
\hline Findep & $-0.514^{* * *}$ & 0.000 & $-0.264^{* * *}$ & 0.000 & $-0.250^{* *}$ & 0.006 \\
Captial & $-0.496^{* *}$ & 0.027 & $-0.253^{* *}$ & 0.016 & $-0.243^{*}$ & 0.058 \\
lnPGDP & $-2.414^{* *}$ & 0.008 & $-1.239^{* *}$ & 0.005 & $-1.174^{* *}$ & 0.024 \\
lnPGDP2 & $0.105^{* *}$ & 0.019 & $0.054^{* *}$ & 0.015 & $0.051^{* *}$ & 0.040 \\
Openess & $-0.748^{* *}$ & 0.002 & $-0.38^{* * *}$ & 0.000 & $-0.367^{* *}$ & 0.018 \\
Pop & $0.651^{* *}$ & 0.418 & 0.323 & 0.412 & 0.328 & 0.436 \\
Ubr & $2.838^{* *}$ & 0.014 & $1.452^{* *}$ & 0.008 & $1.387^{* *}$ & 0.036 \\
Hum & -1.145 & 0.228 & -0.601 & 0.227 & -0.544 & 0.245 \\
Stru & $0.085^{* *}$ & 0.949 & 0.038 & 0.957 & 0.05 & 0.942 \\
Fiscal & 0.147 & 0.736 & 0.078 & 0.721 & 0.069 & 0.756 \\
Consume & -0.544 & 0.317 & -0.279 & 0.306 & -0.265 & 0.343 \\
\hline
\end{tabular}

Note: ${ }^{* * *}, * *$, and ${ }^{*}$ mean significant at $1 \%, 5 \%$, and $10 \%$ levels, respectively.

\subsubsection{Subsample Effect Test}

China's economic development has gone through a process from coastal areas to inland areas. There are obvious differences in economic development level, financial deepening degree, and income structure between urban and rural areas in the eastern, central, and western regions. This difference may also be reflected in the impact of financial deepening on the income disparity between urban and 
rural areas. Therefore, it is necessary to decompose the total effect based on the three regions in order to understand the differences brought by the geographical space.

Table 6 shows the effect decomposition of the spatial lag model in the eastern, central, and western regions. The impact of financial deepening on the income disparity between urban and rural areas is obviously different in the three regions. Judging from the overall effect, the financial deepening in the western region has the strongest effect on reducing the income disparity between urban and rural areas, followed by the eastern region, and the weakest in the central region. This shows that the financial deepening plays a greater role in promoting economic growth in the western and central regions than in the eastern region. This may be partly due to the fact that the financial development in the central and western regions lags far behind that in the eastern region, making the marginal effect of financial deepening on supporting and promoting economic development larger. Financial deepening has a more significant marginal effect on low-income groups and can effectively reduce the income disparity between urban and rural areas. From the direct effect, the western region is obviously larger than the central and eastern regions, indicating that the local effect of financial deepening is very significant. On the contrary, from the perspective of indirect effects, only the eastern region is significant, with strong spillover effects, while the indirect effects in the central and western regions are not significant. This shows that the disparity between urban and rural areas in the central and western regions is more driven by local financial deepening, and the external spillover effect is not obvious. The reasons for this difference may be as follows: the sensitivity of financial deepening to developed regions and less developed regions is different. The marginal effect of financial deepening in developed regions is lower than that in less-developed central and western regions [37], so its direct effect is very significant. However, due to its developed economy and high level of financial development, the spatial spillover effect in the eastern region is relatively obvious, while in the central and western regions, the spatial spillover brought by financial deepening is not significant due to the lag of its economic development stage [38].

Table 6. Decomposition of spillover effects in eastern, central, and western regions.

\begin{tabular}{cccccccc}
\hline \multirow{2}{*}{ Area } & Variable & \multicolumn{2}{c}{ Total Effect } & \multicolumn{2}{c}{ Direct Effect } & \multicolumn{2}{c}{ Indirect Effect } \\
\cline { 3 - 7 } & & Coefficient & $p$-Value & Coefficient & $p$-Value & Coefficient & $p$-Value \\
\hline \multirow{5}{*}{ Eastern } & Findep & $-0.356^{* *}$ & 0.026 & $-0.150^{* *}$ & 0.012 & $-0.206^{*}$ & 0.065 \\
& Captial & $0.698^{*}$ & 0.074 & $0.289^{* *}$ & 0.031 & 0.409 & 0.138 \\
& lnPGDP & -3.261 & 0.148 & $-1.347^{*}$ & 0.098 & -1.914 & 0.212 \\
& lnPGDP2 & $0.189^{*}$ & 0.083 & $0.078^{* *}$ & 0.039 & 0.111 & 0.147 \\
& Openess & -0.215 & 0.286 & -0.086 & 0.241 & -0.129 & 0.336 \\
& Pop & 0.675 & 0.442 & 0.268 & 0.426 & 0.407 & 0.468 \\
& Ubr & $-2.718^{* *}$ & 0.027 & $-1.131^{* *}$ & 0.007 & $-1.587^{*}$ & 0.072 \\
& Hum & $-3.076^{* *}$ & 0.007 & $-1.297^{* *}$ & 0.002 & $-1.779 * *$ & 0.029 \\
& Stru & $4.886^{*}$ & 0.104 & $1.989^{* *}$ & 0.042 & 2.898 & 0.179 \\
& Fiscal & $-1.635^{* *}$ & 0.005 & $-0.667^{* *}$ & 0.008 & $-0.968^{*}$ & 0.115 \\
& Consume & -0.350 & 0.730 & -0.161 & 0.696 & -0.189 & 0.759 \\
\hline \multirow{5}{*}{ Central } & Findep & $-0.264^{* *}$ & 0.017 & $-0.202^{* *}$ & 0.01 & -0.062 & 0.142 \\
& Captial & 0.149 & 0.385 & 0.115 & 0.373 & 0.034 & 0.474 \\
& lnPGDP & $5.213^{* * *}$ & 0.00 & $4.05^{* * *}$ & 0.00 & $1.163 * *$ & 0.033 \\
& lnPGDP2 & $-0.283^{* * *}$ & 0.00 & $-0.219^{* * *}$ & 0.00 & $-0.063 * *$ & 0.029 \\
& Openess & $-1.946^{* *}$ & 0.004 & $-1.490^{* *}$ & 0.002 & -0.457 & 0.111 \\
& Pop & $-1.101^{*}$ & 0.088 & $-0.843^{*}$ & 0.077 & -0.258 & 0.213 \\
& Ubr & -0.048 & 0.960 & -0.043 & 0.951 & -0.004 & 0.987 \\
& Hum & $1.774^{* *}$ & 0.023 & $1.366^{* *}$ & 0.02 & 0.408 & 0.146 \\
& Stru & $1.524^{*}$ & 0.08 & $1.162^{*}$ & 0.065 & 0.362 & 0.224 \\
& Fiscal & -0.107 & 0.653 & -0.081 & 0.651 & -0.025 & 0.679 \\
& Consume & 0.429 & 0.408 & 0.328 & 0.404 & 0.102 & 0.474 \\
\hline
\end{tabular}


Table 6. Cont.

\begin{tabular}{cccccccc}
\hline \multirow{2}{*}{ Area } & \multirow{2}{*}{ Variable } & \multicolumn{2}{c}{ Total Effect } & \multicolumn{2}{c}{ Direct Effect } & \multicolumn{2}{c}{ Indirect Effect } \\
\cline { 3 - 7 } & & Coefficient & $p$-Value & Coefficient & $p$-Value & Coefficient & $p$-Value \\
\hline \multirow{6}{*}{ Western } & Findep & $-0.601^{* * *}$ & 0.001 & $-0.578^{* * *}$ & 0.00 & -0.024 & 0.797 \\
& Captial & -0.182 & 0.354 & -0.174 & 0.337 & -0.008 & 0.840 \\
& lnPGDP & 0.056 & 0.950 & 0.076 & 0.929 & -0.02 & 0.885 \\
& lnPGDP2 & -0.038 & 0.395 & -0.037 & 0.390 & -0.001 & 0.929 \\
& Openess & $-1.323^{* *}$ & 0.016 & $-1.254^{* *}$ & 0.006 & -0.069 & 0.754 \\
& Pop & $1.853^{*}$ & 0.076 & $1.755^{*}$ & 0.054 & 0.097 & 0.776 \\
& Ubr & $5.581^{* *}$ & 0.021 & $5.241^{* *}$ & 0.006 & 0.341 & 0.723 \\
& Hum & -1.469 & 0.195 & -1.439 & 0.196 & -0.03 & 0.906 \\
& Stru & 1.699 & 0.283 & 1.637 & 0.274 & 0.062 & 0.863 \\
& Fiscal & 0.582 & 0.247 & 0.559 & 0.225 & -0.025 & 0.679 \\
& Consume & -0.646 & 0.170 & -0.612 & 0.149 & -0.034 & 0.791 \\
\hline
\end{tabular}

Note: ${ }^{* * *}, * *$, and ${ }^{*}$ mean significant at $1 \%, 5 \%$, and $10 \%$ levels, respectively.

\section{Conclusions}

On the basis of constructing a theoretical model and clearly revealing the impact mechanism of financial development on income distribution, this paper used China's 2002-2013 data for empirical research. The results show that financial deepening has a positive effect on the income distribution of Chinese residents, and a higher level of financial development helps to reduce the inequality of income distribution of Chinese residents. This conclusion is obviously different from the existing studies in China, but it just verifies the G-Z hypothesis put forward by Galor and Zeira (1993), which is recognized by the international academic community: the level of financial development and the inequality of income distribution should have a linear negative correlation in the long run. The above findings show that the widening income distribution disparity in China is not caused by financial development. This discovery provides a basis for us to correctly evaluate China's financial development.

(1). To continuously improve the efficiency of China's financial industry, so that China's financial industry can continuously reduce interest spread or financing costs, so that more low-income and middle-income people can obtain financial services.

(2). To improve the imbalance of regional economic development, change the dual structure of finance between urban and rural areas, speed up the financial construction in rural areas, ease the financing bottleneck of infrastructure construction in rural areas through financial support, further promote the urbanization process, and narrow the income disparity between urban and rural residents.

(3). Problems caused by the lack of financial resources in rural areas and the difficulty for financial institutions to cover them. This paper emphasizes that we should make full use of new digital and information technologies and send financial resources to rural areas through big data online digital banks and national precision poverty alleviation projects. This can not only solve a large amount of bank network coverage costs, but also reduce the transaction costs of financial institutions, improve the efficiency of poverty alleviation in rural areas, and reduce the income equality between urban and rural areas.

\subsection{Implications}

This paper further analyzed the theoretical and empirical mechanism of financial deepening on income inequality between urban and rural areas by constructing financial deepening indicators, using the spatial lag model (SLM), and partial differential decomposition method. Through the introduction of spatial factors, a comprehensive study of the spatial relationship between financial deepening and income inequality between urban and rural areas can make up for the shortcomings of existing research methods and the narrow theoretical perspective. Of course, this research method is not only 
applicable to China, but also can be used to analyze the vast number of emerging market economies and less developed countries to provide research support for the late-developing economies to achieve economic growth while reducing increasing income inequality.

This paper can be used to further deepen the reform of China's financial system, improve the efficiency of financial development, and reduce income inequality between urban and rural areas. Relevant policy suggestions can also provide reference for emerging economies to solve income inequality between urban and rural areas.

\subsection{Limitations and Future Research}

Of course, the research in this paper has certain limitations: for example, the object of the research is the income inequality between urban and rural at the provincial level, which may have certain sample deviation in the research process; using the balance of loans from financial institutions as an indicator to measure financial deepening cannot fully reflect the financial development level of a region. This article will do further follow-up research along with the achievements of relevant scholars. Therefore, by collecting individual data, this paper reveals the mechanism of income inequality between urban and rural areas in China from a micro perspective to make up for the limitations of existing data and research methods. At the same time, through the analysis of the big data of the National Bureau of Statistics on the financial risk preferences of urban and rural residents, as well as their financial investment and consumption habits, a more perfect and reasonable financial deepening index will be further constructed to provide more constructive suggestions for improving the welfare of all citizens and reducing the income disparity between urban and rural areas.

Author Contributions: Conceptualization, L.C.; methodology, L.C.; software, L.C.; validation, M.R. and W.L.; formal analysis, L.C.; investigation, M.R. and W.L.; resources, W.L.; data curation, L.C.; writing-original draft preparation, L.C.; writing-review and editing, M.R. and W.L.; visualization, W.L.; supervision, W.L.; project administration, M.R.; funding acquisition, M.R. All authors have read and agreed to the published version of the manuscript.

Funding: National Social Science Foundation of China: No. 19BJY038.

Acknowledgments: Thank you very much for the constructive comments given by the three anonymous reviewers and Liu. These comments were very helpful for improving the article and improving the quality of the article. Here, thank you again to the three reviewers and Liu.

Conflicts of Interest: The authors declare no conflict of interest.

\section{References}

1. Lu, M.; Chen, Z. Economic policy of urbanization and urban tendency and urban-rural income gap. Econ. Res. 2004, 6, 50-58.

2. Wang, X.; Fan, G. Analysis of the trend and influencing factors of China's income gap. Econ. Res. 2005, 10, 24-36.

3. Shao, Y.; Liu, S.B.; Zhang, C.Y. Financial development model and economic growth under innovation difference: Theory and demonstration. Manag. World 2015, 64, 29-39.

4. Qian, X.; Shen, K. Income gap between urban and rural areas, labor quality and China's economic growth. Econ. Res. 2014, 1, 30-43.

5. Aivi, L.; Yao, Y. Rule of Law under Financial Repression, Financial Development and Economic Growth. Chin. Soc. Sci. 2004, 1, 42-56.

6. Greenwood, J.; Jovanovic, B. Financial Development, Growth, and the Distribution of Income. J. Political Econ. 1990, 98, 1076-1107. [CrossRef]

7. Fan, Q.; Hudson, D. A new construction method of endogenous spatiotemporal weight matrix with variable time effect. Quantitative economic. Technol. Econ. Res. 2018, 1, 142-146.

8. Adelman, I.; Morris, C.T. Economic Growth and Social Equity in Developing Countries; Stanford University Press: Redwood City, CA, USA, 1973; Volume 70, p. 257.

9. Lin, Y.; Liu, M. Convergence of economic growth and income distribution in China. World Econ. 2003, 8, 3-14. 
10. Zhao, Q.; Zhang, C. Financial deepening, FDI spillover effect and regional economic growth: Based on the analysis of provincial panel data from 1997 to 2004. Quant. Econ. Technol. Econ. Res. 2007, 143, 74-82.

11. Goldsmith, R. Financial Structure and Development; Yale University Press: New Haven, CT, USA, 1969.

12. Levine, R. Finance and Growth: Theory and Evidence; Philippe, A., Steven, D., Eds.; Elsevier: Amsterdam, The Netherlands, 2005.

13. King, R.; Levine, R.R. Finance, Entrepreneurship, and Growth: Theory and Evidence. J. Monet. Econ. 1993, 32, 513-542. [CrossRef]

14. Borlea, S.N.; Puscas, A.; Mare, C.; Monica, A. Direction of Causality between Financial Development and Economic Growth. Evidence for Developing Countries. Stud. Univ. "Vasile Goldis" Arad-Econ. Ser. 2016, 26, 1-22. [CrossRef]

15. Baiardi, C.; Morana, D. Financial development and income distribution inequality in the euro area. Econ. Model. 2018, 70, 40-55. [CrossRef]

16. Jauch, S.; Watzka, S. Financial development and income inequality: A panel data approach. Empir. Econ. 2016, 51, 291-314. [CrossRef]

17. Manoel, B.; Shinhye, C.; Rangan, G.; Stephen, M.M. Does financial development affect income inequality in the U.S. States? J. Policy Model. 2019, 41, 1043-1056.

18. Banerjee, A.; Newman, A. Occupational Choice and the Process of Development. J. Political Econ. 1993, 101, 274-298. [CrossRef]

19. Yener, A.; John, T. Finance and income inequality revisited. Finance Res. Lett. 2019. [CrossRef]

20. John, T.; Caterina, D.T. The long-run relationship between finance and income inequality: Evidence from panel data. Finance Res. Lett. 2019. [CrossRef]

21. Mookherjee, D.; Debraj, R. Persistent Inequality. Rev. Econ. Stud. 2003, 70, 369-393. [CrossRef]

22. Hamori, S.; Hashiguchi, Y. The effect of financial deepening on inequality: Some international evidence. J. Asian Econ. 2012, 23, 353-359. [CrossRef]

23. Clarke, G.R.G.; Xu, L.C.; Zou, H. Finance and Income Inequality: What Do the Data Tell Us? South. Econ. J. 2006, 72, 578-596. [CrossRef]

24. Beck, T.; Demirgüç-Kunt, A.; Levine, R. Finance, Inequality, and the Poor. J. Econ. Growth 2007, 12, 27-49. [CrossRef]

25. Dong, X.; Zhang, X. The impact of financial development on the income gap between urban and rural residents: An empirical study based on a spatial econometric model. J. Nanjing Agric. Univ. (Soc. Sci. Ed.) 2013, 3, 33-39.

26. Yang, J.; Li, X.; Zhang, Z. An Empirical Analysis of China's Financial Development Level and Income Distribution of Residents. Econ. Sci. 2006, 2, 23-33.

27. Zhang, W.; Xu, L.; Luo, Z. Financial Development and Income Inequality: Back to the G-Z Hypothesis. Contemp. Finance 2010, 11, 14-26.

28. Cai, F.; Yang, T. Political Economy of the Urban-rural Income Gap. Chin. Soc. Sci. 2000, 4, 11-22.

29. Anselin, L.; Bera, A.K. Spatial Dependence in Linear Regression Models with an Introduction to Spatial Econometrics. Stat. Textb. Monogr. 1998, 155, 237-289.

30. Anselin, L. Thirty years of spatial econometrics. Pap. Reg. Sci. 2010, 89, 3-25. [CrossRef]

31. Fan, Q.; Shi, M. Endogenous spatio-temporal weight matrix selection method based on structural matching and effective correlation. Quant. Econ. Res. 2018, 9, 114-135.

32. Gu, X.; Chen, Y.; Pan, S. Uncertainty and Innovation of Economic Policy-Based on Empirical Analysis of Listed Companies in China. Econ. Res. 2018, 2, 109-123.

33. LeSage, J.; Pace, R.K. Introduction to Spatial Econometrics; CRC Press: New York, NY, USA, 2009.

34. Behrens, K.; Thisse, J.F. Regional economics: A new economic geography perspective. Reg. Sci. Urban Econ. 2007, 37, 457-465. [CrossRef]

35. Odedokun, M.O. Alternative econometric approaches for analyzing the role of the financial sector in economic growth: Time-series evidence from LDCs. J. Dev. Econ. 1996, 50, 119-146. [CrossRef]

36. Ndalu, C. Financial Deepening of Insurance and Economic Growth in Kenya. Int. J. Acad. Res. Account. Finance Manag. Sci. 2016, 6, 7-14. [CrossRef] 
37. Zhang, L.; Zhan, Y. Analysis and Test of Three Major Effects of Financial Development on Urban-rural Income Gap. J. Quant. Tech. Econ. 2006, 12, 73-82.

38. Li, C.; Zhang, Q. Research on the Interfnal Mechanism of the Decreasing Marginal Effect of Financial Development on Economic Growth: A Theoretical Framework Based on the "Two-sector Division Method". Econ. Sci. 2015, 5, 5-17. 